\title{
EFFECT OF SUPPLEMENTATION OF LIMITING AMINO ACIDS ON TYROSINE TOXICITY IN RATS FED WHEAT GLUTEN DIETS
}

\author{
Yukiko Yamamoto, Yasuhiro Orita, and Keiichiro Muramatsu ${ }^{1}$ \\ Laboratory of Food and Nutrition, Department of Agricultural Chemistry, \\ Faculty of Agriculture, Shizuoka University, Shizuoka
}

(Received August 30, 1976)

\begin{abstract}
Summary The effect of supplementation of limiting amino acids on rats fed a 10 or $20 \%$ wheat gluten diet containing $5 \%$ tyrosine has been investigated. Growth-limiting amino acids in a $20 \%$ wheat gluten diet were lysine and threonine. When rats were fed a $20 \%$ wheat gluten diet containing excess tyrosine, the addition of $1.0 \%$ lysine $\cdot \mathrm{HCl}$ or $1.0 \%$ lysine $\cdot \mathrm{HCl}$ and $0.4 \%$ threonine completely prevented the development of tyrosine toxicity, and was accompanied by a lowering of free tyrosine concentrations in plasma, liver and muscle. In rats receiving a $10 \%$ wheat gluten diet, lysine, threonine and methionine were limiting for growth. The addition of $1.0 \%$ lysine $\cdot \mathrm{HCl}$ to the $10 \%$ wheat gluten plus $5 \%$ tyrosine diet failed to alleviate the tyrosine toxicity, but the supplement of $1.0 \%$ lysine $\cdot \mathrm{HCl}$ and $0.4 \%$ threonine could partially alleviate the toxicity. The combined addition of $1.0 \%$ lysine $\cdot \mathrm{HCl}, 0.4 \%$ threonine and $0.5 \%$ methionine was most effective. The free tyrosine concentrations in plasma, liver and muscle were lowered greatly by the supplementation of three limiting amino acids, but amounts of free tyrosine and phenolic metabolites excreted in the urine did not decrease with addition of these limiting amino acids.
\end{abstract}

It has been shown in young rats fed a low protein diet containing excess tyrosine, that the growth is retarded and eye and paw lesions develop (1-6). Recently we found that the growth depression and appearance of pathological lesions which developed in rats fed a $10 \%$ casein diet containing $5 \%$ tyrosine were alleviated by the supplement of methionine and threonine, the first and second limiting amino acids respectively, in the diet $(7,8)$.

On the other hand, it was also demonstrated in our laboratory (9) that the tyrosine toxicity produced by feeding an $11.6 \%$ wheat gluten diet containing $5 \%$ tyrosine (equivalent in $\mathrm{N}$ content to $10 \%$ casein) was not at all alleviated by the

\footnotetext{
${ }^{1}$ 山本由喜子，折田泰洋，村松敬一郎
} 
first limiting amino acid, lysine. The amounts of some amino acids such as threonine and methionine are also insufficient in the low wheat gluten diet $(10,11)$, but the effect of these limiting amino acids in wheat gluten on tyrosine toxicity had not been investigated.

Therefore, the present study was performed in an attempt to elucidate the effect of those limiting amino acids in wheat gluten on tyrosine toxicity. Growth depression, free tyrosine concentration in plasma, liver and muscle, together with urinary excretion of tyrosine and its phenolic metabolites were determined.

\section{EXPERIMENTAL}

Animals and diets. Male weanling rats of the Wistar strain were fed a stock diet ( $25 \%$ casein) for 3 to 4 days prior to starting the experiments. Rats weighing 60 to $65 \mathrm{~g}$ were divided into two series and separated into several experimental groups of five animals each (Table 1).

In experiment I, 20\% wheat gluten ${ }^{2}$ was used in each group, and $5 \% \mathrm{~L}$-tyrosine

Table 1. Composition of experimental diets. ${ }^{a}$

\begin{tabular}{|c|c|c|c|c|c|c|c|}
\hline $\begin{array}{l}\text { Dietary } \\
\text { groups }\end{array}$ & $\begin{array}{l}\text { Wheat } \\
\text { gluten }\end{array}$ & $\begin{array}{c}\mathrm{L}- \\
\text { Tyrosine }\end{array}$ & $\begin{array}{c}\text { L-Lysine. } \\
\mathrm{HCl}\end{array}$ & $\begin{array}{c}\mathrm{L}- \\
\text { Threonine }\end{array}$ & $\begin{array}{c}\text { L- } \\
\text { Methionine }\end{array}$ & $\begin{array}{l}\mathrm{L}-\text {-His- } \\
\text { tidine } \cdot \mathrm{HCl}\end{array}$ & $\begin{array}{c}\text { L-Trypto- } \\
\text { phan }\end{array}$ \\
\hline \multicolumn{3}{|c|}{ Experiment I } & \multicolumn{3}{|c|}{$(\%)$} & & \\
\hline $20 \mathrm{G}$ & 20 & - & - & - & - & - & - \\
\hline 20G Lys & 20 & - & 1.0 & - & - & - & - \\
\hline 20G Lys Thr & 20 & - & 1.0 & 0.4 & - & - & - \\
\hline & - \\
\hline Met His Trp & 20 & - & 1.0 & 0.4 & 0.5 & 0.3 & 0.1 \\
\hline 20G Thr Met & 20 & - & - & 0.4 & 0.5 & - & - \\
\hline $20 \mathrm{G} 5 \mathrm{~T}$ & 20 & 5 & - & - & - & - & - \\
\hline 20G5T Lys & 20 & 5 & 1.0 & - & - & - & - \\
\hline 20G5T Lys Thr & 20 & 5 & 1.0 & 0.4 & - & - & - \\
\hline \multicolumn{8}{|l|}{ 20G5T Lys Thr } \\
\hline Met & 20 & 5 & 1.0 & 0.4 & 0.5 & - & - \\
\hline \multicolumn{8}{|l|}{ 20G5T Lys Thr } \\
\hline Met His Trp & 20 & 5 & 1.0 & 0.4 & 0.5 & 0.3 & 0.1 \\
\hline 20G5T Thr Met & 20 & 5 & - & 0.4 & 0.5 & - & - \\
\hline \multicolumn{8}{|c|}{ Experiment II } \\
\hline $10 \mathrm{G}$ & 10 & - & - & - & - & - & - \\
\hline 10G Lys & 10 & - & 1.0 & - & - & - & - \\
\hline 10G Lys Thr & 10 & - & 1.0 & 0.4 & - & - & - \\
\hline 10G Lys Thr Met & 10 & - & 1.0 & 0.4 & 0.5 & - & - \\
\hline 10G5T & 10 & 5 & - & - & - & - & - \\
\hline 10G5T Lys & 10 & 5 & 1.0 & - & - & - & - \\
\hline 10G5T Lys Thr & 10 & 5 & 1.0 & 0.4 & - & - & - \\
\hline 10G5T Lys Thr Met & et 10 & 5 & 1.0 & 0.4 & 0.5 & - & - \\
\hline
\end{tabular}

a The other components of experimental diets have been described in the text.

${ }^{2}$ Hi-Pro, Shin-shin Food Industry Co., Ltd., Tokyo; the protein content on the basis of kjeldahl $\mathrm{N} \times 5.70$ was $71.0 \%$. 
was added to the last six groups. In addition, some growth-limiting amino acids of wheat gluten, i.e. L-lysine, L-threonine, L-methionine, L-histidine and L-tryptophan were added to some groups in various combinations.

In experiment II, 10\% wheat gluten was used, and 5\% L-tyrosine was added to the last four groups. L-Lysine, L-lysine and L-threonine, or L-lysine, L-threonine and L-methionine were added to some groups. The supplemental level of these amino acids was sufficient to fulfill the requirements of growing rats (10).

The composition of the $20 \%$ wheat gluten diet (in \%) was as follows: wheat gluten 20.0, salt mixture ${ }^{3}$ (12) 5.0, vitamin mixture ${ }^{2}$ (12) 1.0 , choline chloride ${ }^{3} 0.1$, soybean oil 5.0, and $\alpha$-corn starch $^{3}$ 68.9. The diet also contained $0.07 \mathrm{ml}$ of Chocola $\mathrm{A}^{4}$ per $100 \mathrm{~g}$ of diet. Variations in the amounts of added amino acids were made at the expense of $\alpha$-starch. Food and water were provided ad libitum. During experimental periods all animals were individually housed in suspended screen-bottom cages and kept at a temperature of $24^{\circ} \mathrm{C}$ with a lighting period from 8: $00 \mathrm{AM}$ to 8:00 PM. Body weights were recorded daily, and food consumptions were determined on a dry material basis.

Analysis of urine. In experiment II, the urine was collected in $6 \mathrm{~N} \mathrm{HCl}(20 \mathrm{ml})$ for each 2-day period, i.e. for days 2 and 3, 7 and 8, and 13 and 14, respectively. The collected urine was diluted with distilled water to a final volume of $250 \mathrm{ml}$. Aliquots of diluted urine were heated for one hour in a boiling water bath. Total phenols, $p$-hydroxyphenylpyruvic acid (pHPPA) and volatile phenols in acidhydrolyzed urine were determined using the method of BERNHART and ZILLIKEN (13). It was confirmed that so called volatile phenols were not lost at all in these procedures. Homogentisic acid in the unhydrolyzed urine was determined by the micro-iodometric titration method of Neuberger (14).

Tyrosine determination. At the end of the experimental period, the rats were decapitated after a 6-hr fast and bled into heparinized test tubes. After centrifugation, samples of plasma were separated and deproteinized with an equal volume of $30 \%$ trichloroacetic acid and three volumes of water. Liver, which was perfused in situ with ice-cold $0.9 \% \mathrm{NaCl}$ solution, and muscle of hind legs were homogenized in an equal volume of $30 \%$ trichloroacetic acid and three volumes of water. The deproteinized clear supernatants of plasma, liver and muscle were used for tyrosine determination. Free tyrosine concentration was determined by the method of Udenfriend and Cooper (15).

\section{RESULTS}

\section{Weight gain and food intake}

The supplement of $1.0 \%$ lysine $\cdot \mathrm{HCl}$ and $0.4 \%$ threonine to the $20 \%$ wheat gluten diet (20G Lys Thr) resulted in the greatest weight gain, and the addition of

\footnotetext{
${ }^{3}$ Tanabe Amino Acids Research Co., Osaka.

${ }^{4}$ Vitamin A, 30,000 IU and vitamin $\mathrm{D}_{2}, 3,000 \mathrm{IU}$ per ml. Eizai Co., Ltd., Tokyo.
} 


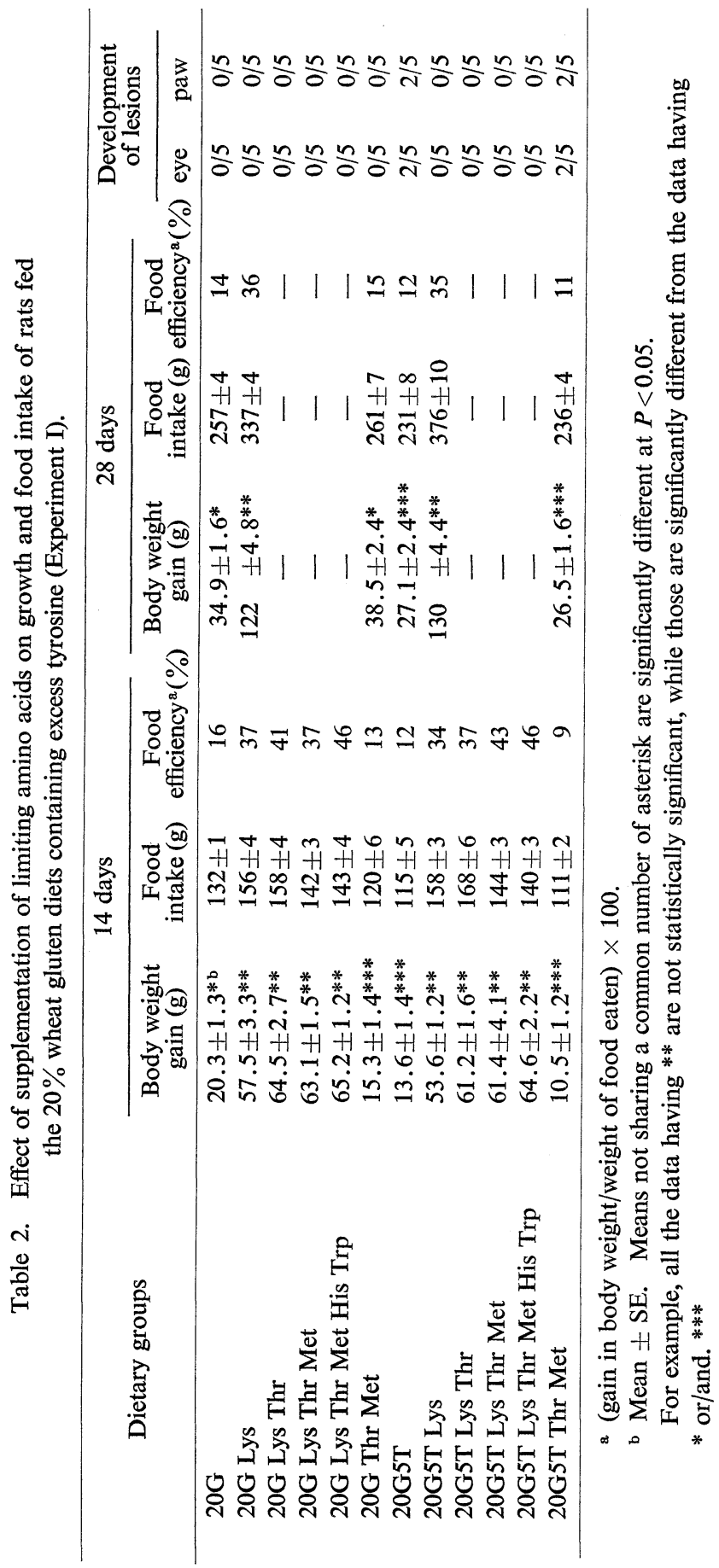


$1.0 \%$ lysine $\cdot \mathrm{HCl}$ alone to the $20 \%$ wheat gluten diet ( $20 \mathrm{G}$ Lys) produced a weight gain of $95 \%$ of that found in the 20G Lys Thr group (Table 2). When rats were fed the $20 \%$ wheat gluten diet containing $5 \%$ tyrosine $(20 \mathrm{G} 5 \mathrm{~T})$ a growth depression was produced and two out of five animals suffered from pathological lesions of the eye and paw after three weeks. In rats receiving the 20G Lys diet including $5 \%$ tyrosine (20G5T Lys), pathological lesions were not observed and the growth depression was partially alleviated. When $0.4 \%$ threonine and $0.5 \%$ methionine were supplemented in the $20 \%$ wheat gluten diet without additional lysine (20G Thr Met), growth retardation was produced, and the inclusion of $5 \%$ tyrosine in the diet (20G5T Thr Met) caused eye and paw lesions in two out of five animals.

In rats given wheat gluten at the $10 \%$ level, the combined addition of $1.0 \%$ lysine $\cdot \mathrm{HCl}, 0.4 \%$ threonine and $0.5 \%$ methionine (10G Lys Thr Met) was most effective in growth stimulation (Table 3). When excess tyrosine was included

Table 3. Effect of supplementation of limiting amino acids on growth and food intake of rats fed the $10 \%$ wheat gluten diets containing excess tyrosine (Experiment II).

\begin{tabular}{lccccc}
\hline $\begin{array}{c}\text { Dietary } \\
\text { groups }\end{array}$ & $\begin{array}{c}\text { Body weight } \\
\text { gain (g/14 days) }\end{array}$ & $\begin{array}{c}\text { Food intake } \\
(\mathrm{g} / 14 \text { days })\end{array}$ & $\begin{array}{c}\text { Food } \\
\text { efficiency } \\
(\%)\end{array}$ & \multicolumn{2}{c}{ Development of lesions } \\
\cline { 5 - 6 } & $8.0 \pm 1.0^{\mathrm{b} *}$ & $111 \pm 5$ & 7.1 & $0 / 5$ & $0 / 5$ \\
10G & $19.7 \pm 2.7^{* * *}$ & $130 \pm 8$ & 14.9 & $0 / 5$ & $0 / 5$ \\
10G Lys & $51.5 \pm 1.7^{* * * *}$ & $158 \pm 4$ & 32.7 & $0 / 5$ & $0 / 5$ \\
10G Lys Thr & $56.9 \pm 2.4^{* * * *}$ & $160 \pm 6$ & 35.7 & $0 / 5$ & $0 / 5$ \\
10G Lys Thr Met & $-4.9 \pm 0.8^{* *}$ & $77 \pm 3$ & -4.8 & $5 / 5$ & $5 / 5$ \\
10G5T & $1.0 \pm 0.9^{* *}$ & $84 \pm 3$ & 1.9 & $5 / 5$ & $5 / 5$ \\
10G5T Lys & $23.8 \pm 3.9^{* * *}$ & $115 \pm 8$ & 20.1 & $0 / 5$ & $0 / 5$ \\
10G5T Lys Thr & $46.0 \pm 4.7^{* * * *}$ & $143 \pm 8$ & 32.0 & $0 / 5$ & $0 / 5$ \\
10G5T Lys Thr Met & 46.8 &
\end{tabular}

a See Table 2.

b Mean \pm SE. Means not sharing a common number of asterisk are significantly different at $P<0.05$.

in the $10 \%$ gluten diet (10G5T), severe growth depression was caused and all animals suffered from eye and paw lesions. Addition of lysine $\cdot \mathrm{HCl}$ alone to the diet (10G5T Lys) could alleviate neither growth retardation nor eye and paw lesions. When $1.0 \%$ lysine $\cdot \mathrm{HCl}$ and $0.4 \%$ threonine were supplemented to 10G5T diet (10G5T Lys Thr), the growth depression due to excess tyrosine was partially alleviated and the pathological lesions diminished. When $0.5 \%$ methionine was added to the diet (10G5T Lys Thr Met), the growth was stimulated and the weight gain was about $92 \%$ of that found in the 10G Lys Thr Met group.

Ratio of weight gain to food intake correlated well with changes in body weight (Experiments I and II).

Tissue tyrosine concentrations

Table 4 shows the concentration of total phenols in plasma, and free tyrosine 
concentrations in plasma, liver and muscle. When rats were fed the 20G5T diet, tyrosine concentrations were elevated very markedly in plasma, liver and muscle. Addition of lysine, the first limiting amino acid, to the diet effectively lowered free tyrosine levels of plasma, liver and muscle, although their values exceeded slightly that for the 20G group. The plasma tyrosine levels in animals fed the 20G5T Thr Met diet were not lowered; in fact the levels in liver and muscle exceeded even those in the 20G5T group.

Table 4. Effect of supplementation of limiting amino acids on total phenols and free tyrosine concentrations in plasma, liver and muscle of rats fed the $10 \%$ and $20 \%$ wheat gluten diets containing excess tyrosine.

\begin{tabular}{|c|c|c|c|c|c|}
\hline \multirow{2}{*}{ Dietary groups } & \multirow{2}{*}{\multicolumn{2}{|c|}{$\frac{\text { Total phenols }}{\text { Plasma } \mathrm{mg} / 100 \mathrm{ml}}$}} & \multicolumn{3}{|c|}{ Free tyrosine } \\
\hline & & & Plasma mg/100ml & Liver $\mathrm{mg} / \mathrm{g}$ & Muscle mg/g \\
\hline \multicolumn{6}{|c|}{ Experiment I (28 days) } \\
\hline $20 \mathrm{G}$ & & - & $0.7 \pm 0.1^{\mathrm{a} *}$ & $0.07 \pm 0.01 *$ & $0.02 \pm 0.01 *$ \\
\hline 20G5T & & - & $31.9 \pm 0.8^{* * *}$ & $0.13 \pm 0.03$ & $0.50 \pm 0.02^{* * *}$ \\
\hline 20G5T Lys & & - & $6.5 \pm 0.6^{* *}$ & $0.10 \pm 0.01^{* *}$ & $0.13 \pm 0.01^{* *}$ \\
\hline 20G5T Thr Met & & - & $24.4 \pm 7.1^{* * *}$ & $0.27 \pm 0.10$ & $0.71 \pm 0.25^{* * *}$ \\
\hline \multicolumn{6}{|c|}{ Experiment II (14 days) } \\
\hline $10 \mathrm{G}$ & & $9 \pm 0.8^{*}$ & $1.0 \pm 0.1^{*}$ & $0.07 \pm 0.01 *$ & $0.01 \pm 0.002^{*}$ \\
\hline $10 \mathrm{G} 5 \mathrm{~T}$ & 118 & $\pm 20^{* * *}$ & $53.8 \pm 6.3^{* * *}$ & $0.26 \pm 0.06$ & $0.30 \pm 0.09^{* *}$ \\
\hline 10G5T Lys & 115 & $\pm 20^{* * *}$ & $45.6 \pm 9.4^{* * *}$ & $0.27 \pm 0.06^{* * *}$ & $0.61 \pm 0.16^{* * *}$ \\
\hline 10G5T Lys Thr & 125 & $\pm 15^{* * *}$ & $50.6 \pm 8.2^{* * *}$ & $0.34 \pm 0.06^{* * *}$ & $0.78 \pm 0.22 * * *$ \\
\hline 10G5T Lys Thr Met & 39 & $\pm 13^{* *}$ & $6.8 \pm 1.8^{* *}$ & $0.13 \pm 0.02^{* *}$ & $0.14 \pm 0.05^{* *}$ \\
\hline
\end{tabular}

${ }^{2}$ Mean \pm SE. Means not sharing a common number of asterisk are significantly different at $P<0.05$.

Supplementing lysine, threonine and methionine in the 10G5T diet caused a lowering of the levels of total phenols in plasma, and of free tyrosine in plasma, liver and muscle, whereas the addition of lysine alone or lysine and threonine to the 10G5T diet was not only effective in lowering the levels of total phenols and free tyrosine in plasma but elevated free tyrosine levels in liver and muscle.

\section{Urine analysis}

A large increase in excreted amounts of total phenols, pHPPA and free tyrosine in urine was observed in rats fed the 10G5T diet (Table 5). When lysine and threonine or lysine, threonine and methionine were supplemented in the diet, the growth depression was alleviated as shown in Table 3. Urinary excretion of pHPPA and free tyrosine was not lowered and amounts of volatile phenols and homogentisic acid were higher than those in the 10G5T group.

\section{DISCUSSION}

In an early study (9) we observed that the toxic effect of tyrosine, which deve- 
Table 5. Effect of supplementation of limiting amino acids on urinary excretion of total phenols, tyrosine metabolites and free tyrosine in rats fed the $10 \%$ wheat gluten diets containing excess tyrosine.

\begin{tabular}{|c|c|c|c|c|c|c|}
\hline Days & $\begin{array}{l}\text { Dietary } \\
\text { groups }\end{array}$ & $\begin{array}{l}\text { Total } \\
\text { phenols }\end{array}$ & \multicolumn{2}{|c|}{$\begin{array}{l}\text { Volatile Total ketonic } \\
\text { phenols acids (pHPPA) } \\
\text { (mg } / 2 \text { days) }\end{array}$} & $\begin{array}{c}\text { Homogentisic } \\
\text { acid }\end{array}$ & Tyrosine \\
\hline \multirow{7}{*}{$1-3$} & $10 \mathrm{G}$ & $21 \pm 1^{a *}$ & $4 \pm 0.2^{*}$ & $8 \pm 0.5^{*}$ & $1.5 \pm 0.2^{*}$ & $0.9 \pm 0.1^{*}$ \\
\hline & $10 \mathrm{G} 5 \mathrm{~T}$ & $223 \pm 18^{* *}$ & $133 \pm 14^{* *}$ & $51 \pm 3^{* *}$ & $1.7 \pm 0.1^{*}$ & $13 \pm 4^{* *}$ \\
\hline & 10G5T Lys & $242 \pm 14^{* *}$ & $118 \pm 12^{* *}$ & $48 \pm 5^{* *}$ & $3.0 \pm 0.3^{* * *}$ & $16 \pm 3^{* *}$ \\
\hline & 10G5T Lys & & & & & \\
\hline & Thr & $198 \pm 23^{* *}$ & $131 \pm 16^{* *}$ & $37 \pm 4^{* * *}$ & $1.4 \pm 0.1^{*}$ & $10 \pm 2^{* *}$ \\
\hline & 10G5T Lys & & & & & \\
\hline & Thr Met & $247 \pm 18^{* *}$ & $177 \pm 2^{* * *}$ & $38 \pm 3^{* * *}$ & $2.2 \pm 0.6^{* *}$ & $10 \pm 1^{* *}$ \\
\hline \multirow{7}{*}{$6-8$} & $10 \mathrm{G}$ & $18 \pm 2^{*}$ & $2 \pm 1^{*}$ & $10 \pm 1^{*}$ & $0.7 \pm 0.1^{*}$ & $1 \pm 0.1^{*}$ \\
\hline & $10 \mathrm{G} 5 \mathrm{~T}$ & $359 \pm 20^{* *}$ & $94 \pm 15^{* *}$ & $70 \pm 6^{* *}$ & $0.7 \pm 0.1^{*}$ & $27 \pm 1^{* *}$ \\
\hline & 10G5T Lys & $403 \pm 21^{* *}$ & $120 \pm 14^{* *}$ & $69 \pm 5^{* *}$ & $1.2 \pm 0.2^{*}$ & $32 \pm 3^{* *}$ \\
\hline & 10G5T Lys & & & & & \\
\hline & Thr & $438 \pm 35^{* *}$ & $144 \pm 14^{* * *}$ & $66 \pm 6^{* *}$ & $42.5 \pm 28.1^{* *}$ & $25 \pm 2^{* *}$ \\
\hline & 10G5T Lys & & & & & \\
\hline & Thr Met & $391 \pm 52 * *$ & $169 \pm 11^{* * * *}$ & $58 \pm 6^{* *}$ & $75.1 \pm 25.4^{* * *}$ & $12 \pm 1^{* * *}$ \\
\hline \multirow{7}{*}{$12-14$} & $10 \mathrm{G}$ & $13 \pm 1^{*}$ & $3 \pm 1^{*}$ & $10 \pm 1^{*}$ & $0.8 \pm 0.1^{*}$ & $0.5 \pm 0.02^{*}$ \\
\hline & $10 \mathrm{G} 5 \mathrm{~T}$ & $232 \pm 25^{* *}$ & $56 \pm 4^{* *}$ & $69 \pm 9^{* *}$ & $0.8 \pm 0.1^{*}$ & $20 \pm 4^{* *}$ \\
\hline & 10G5T Lys & $301 \pm 11^{* * *}$ & $74 \pm 3^{* *}$ & $75 \pm 3^{* *}$ & $0.9 \pm 0.1^{*}$ & $23 \pm 1^{* *}$ \\
\hline & 10G5T Lys & & & & & \\
\hline & Thr & $389 \pm 60^{* * *}$ & $203 \pm 23^{* * *}$ & $91 \pm 11^{* * *}$ & $49.2 \pm 22.4^{*}$ & $26 \pm 3^{* *}$ \\
\hline & 10G5T Lys & & & & & \\
\hline & Thr Met & $445 \pm 47 * * *$ & $194 \pm 2^{* * *}$ & $101 \pm 5^{* * * *}$ & $124 \pm 9.0^{* *}$ & $27 \pm 6^{* *}$ \\
\hline
\end{tabular}

a Mean \pm SE. Means not sharing a common number of asterisk are significantly different at $P<0.05$.

loped in rats fed a low wheat gluten diet containing excess tyrosine was not alleviated by addition of lysine, the first limiting amino acid. The present study confirmed that the growth retardation and the pathological lesions which developed in animals fed the $10 \%$ wheat gluten-high tyrosine diet were alleviated by the concomitant supplement of three limiting amino acids, lysine, threonine and methionine, but not by the addition of lysine alone. Furthermore, when $20 \%$ wheat gluten was used as the source of dietary protein, the tyrosine toxicity could be overcome by adding lysine alone or both lysine and threonine. The first and second limiting amino acids in this diet were lysine and threonine, respectively.

Another report (7) indicated that, when $10 \%$ casein was used as the protein source, the tyrosine toxicity was partially alleviated by the addition of methionine alone. In addition the growth retardation could be markedly reversed and the pathological lesions completely prevented by the supplement of both methionine and threonine which are limiting in this diet. Thus, the findings in the present and previous studies $(7,8)$ demonstrate clearly that the addition of the limiting 
amino acids to a low protein-high tyrosine diet has a beneficial effect in alleviating the toxicity.

The adverse effects resulting from amino acid additions can be classified by ElvehJEM (16) and HARPER (17) into three categories: "toxicity," "antagonism" and "imbalance." Detrimental effects due to ingestion of diets containing excess amino acids have in general been included in amino acid "toxicity." However, it is suggested that in the case of tyrosine toxicity, the "toxicity" somewhat resembles a phenomenon of "imbalance," which is prevented by a small supplement of the limiting amino acid(s).

The present investigation has also demonstrated that the beneficial effect of the limiting amino acid supplements in reducing the toxicity in animals fed wheat gluten-high tyrosine diets was accompanied by a lowering of free tyrosine concentrations in plasma and tissues. This is in agreement with the results reported previously $(8)$, in which the high levels of free tyrosine in plasma and tissues of animals fed the $10 \%$ casein diet containing excess tyrosine were lowered significantly by the addition of the limiting amino acids, methionine and threonine. Alam et al. (2) have also shown that the supplement of threonine to a $6 \%$ casein diet containing excess tyrosine lowered the tyrosine concentration in plasma, liver, muscle and eye (3).

On the other hand, amounts of phenolic metabolites of tyrosine excreted in the urine of rats fed the low wheat gluten-high tyrosine diet supplemented with limiting amino acids, lysine, threonine and methionine, did not decrease significantly, as was the case in the results of a previous report (8) in which low caseinhigh tyrosine diet was supplemented by methionine and threonine. It would seem likely that the phenolic metabolite level in urine dose not reflect the tyrosine toxicity.

\section{REFERENCES}

1) Alam, S. Q., Becker, R. V., Stucki, W. P., Rogers, Q. R., and Harper, A. E. (1966): Effect of threonine on the toxicity of excess tyrosine and cataract formation in the rat. J. Nutr., 89, 91-96.

2) Alam, S. Q., Rogers, Q. R., and Harper, A. E. (1966): Effect of tyrosine and threonine on free amino acids in plasma, liver, muscle, and eye in the rat. J. Nutr., 89, 97-105.

3) Boctor, A. M., and Harper, A. E. (1968): Tyrosine toxicity in the rat: Effect of high intake of $p$-hydroxyphenylpyruvic acid and of force-feeding high tyrosine diet. J. Nutr., 95, 535-540.

4) Harper, A. E., Benevenga, N. J., and Wohlheuter, R. M. (1970): Effects of ingestion of disproportionate amounts of amino acids. Physiol. Rev., 50, 428-558.

5) IP, C. C. Y., and HARPER, A. E. (1973): Effects of dietary protein content and glucagon administration on tyrosine metabolism and tyrosine toxicity in the rat. J. Nutr., 103, 1594 1607.

6) Muramatsu, K., Takei, M., and Nakamura, K. (1975): Effect of dietary protein on tyrosine toxicity in the rat. J. Nutr., 105, 439-446.

7) Muramatsu, K., Arito, T., and Tsuda, H. (1976): Effect of individual amino acid sup- 
plements on the toxicity of excess tyrosine in rats. J. Nutr. Sci. Vitaminol., 22, 397-403.

8) Yamamoto, Y., Katayama, H., and Muramatsu, K. (1976): Beneficial effect of methionine and threonine supplements on tyrosine toxicity in rats. J. Nutr. Sci. Vitaminol., 22, 467475.

9) Muramatsu, K., and Sakurai, K. (1973): Supplemental effect of lysine on growth depression of rats fed wheat gluten diets containing excess amounts of some individual amino acids. J. Nutr. Sci. Vitaminol., 19, 513-521.

10) Gupta, J. D., Dakroury, A. M., Harper, A. E., and Elvehjem, C. A. (1958): Biological availability of lysine. J. Nutr., 64, 259-270.

11) Howe, E. E., and Dooley, C. L. (1963): Effect of delayed supplementation of wheat gluten with lysine and threonine on its capacity to promote growth in the weanling rat. J. Nutr., 81, 379-382.

12) HARPER, A. E. (1959): Amino acid balance and imbalance. 1. Dietary level of protein and amino acid imbalance. J. Nutr., 68, 405-418.

13) Bernhart, F. W., and Zilliken, A. (1959): Effect of dietary carbohydrate and chlortetracycline on the growth and excretion of phenols in rats fed extra tyrosine. Arch. Biochem. Biophys., 82, 462-471.

14) Neuberger, A. (1947): Studies on alcaptonuria. 1. The estimation of homogentisic acid. Biochem. J., 41, 431-438.

15) UdENFRIEND, S., and COOPER, J. R. (1952): The chemical estimation of tyrosine and tyramine. J. Biol. Chem., 196, 227-233.

16) Elvehjem, C. A. (1956): Amino acid imbalance. Fed. Proc., 15, 965-970.

17) Harper, A. E. (1958): Balance and imbalance of amino acids. Ann. N. Y. Acad. Sci., 69, 1025-1041. 